\title{
A desconfiança nas instituições democráticas
}

\author{
José Álvaro Moisés \\ Universidade de São Paulo
}

\begin{abstract}
Resumo
Ao mesmo tempo em que apóiam o regime democrático per se, os brasileiros revelam uma ampla e contínua desconfiança em suas instituições. O autor apresenta os fundamentos da convivência entre esses dois fenômenos e em seguida, partindo do tratamento dado pela literatura ao conceito de confiança política e dos fatores a ela associados (por exemplo, legitimidade política e desempenho econômico dos governos), propõe que a confiança nas instituições radica-se na avaliação que os cidadãos, partindo de sua experiência, fazem do modo como aquelas desempenham a missão para a qual foram criadas.
\end{abstract}

Palavras-chave: instituições democráticas, confiança política, experiência, cidadãos.

\section{Abstract}

Several studies show that brazilians support the democratic regime per se, but, at the same time, reveal a widespread and persistent mistrust of democratic institutions. The author begins presenting the foundations of the contradictory coexistence of both phenomena and after that he reviews the treatment given by literature on political trust and the factors related to it (as political legitimacy and economic performance of governments), pointing limits. He also proposes that trust in institutions is rooted on the evaluation citizens make, based on their experience, about the way institutions perform the mission for which they were created.

Keywords: democratic institutions, political trust, experience, citizens. 


\footnotetext{
A esperança constante chama-se confiança... O desespero constante chama-se desconfiança..." Thomas Hobbes, em 1.651.
}

A democracia brasileira está relativamente consolidada - a maior parte dos especialistas reconhece isso. Mas ela enfrenta um paradoxo: as instituições democráticas são objeto de ampla e continuada desconfiança dos cidadãos brasileiros. Pesquisas recentes mostram que, apesar do apoio ao regime democrático per se, cerca de 2/3 dos brasileiros não confiam - em diferentes graus - em parlamentos, partidos, executivos, tribunais de justiça e serviços públicos de saúde, educação e segurança. Surveys realizados entre 1989 e 1993 revelaram que a percepção negativa das instituições atravessa todos os segmentos de renda, escolaridade, idade e distribuição ecológica, chegando a influir sobre a disposição dos cidadãos para participar de processos políticos, como a escolha de governos (MOISÉS, 1995).

Este cenário contrasta com a evolução política recente do país. Ao completar duas décadas de experiência democrática, o Brasil parece ter ingressado em um ciclo virtuoso: vive um período de estabilidade política, contrariando o padrão de décadas anteriores, quando conflitos políticos assumiram a feição de antagonismos inconciliáveis, gerando paralisia decisória, tensões entre o executivo e o legislativo e a intervenção de militares na política. No presente, as instituições democráticas funcionam com relativa harmonia, as forças armadas desempenham seu papel legal e os ciclos eleitorais sucedem-se de acordo com as normas constitucionais.

Desconfiança expressa atitude de descrédito ou desmerecimento de alguém ou de algo, embora, na democracia, alguma dose de desconfiança em instituições possa ser sinal sadio de distanciamento dos cidadãos de uma esfera da vida social sobre a qual têm pouco controle (WARREN, 2001; PETTIT,1998; SZTOMPKA, 1999; USLANER, 2001). Mas a desconfiança em excesso e, sobretudo, com continuidade no tempo, pode significar que, tendo em conta as suas orientações normativas, expectativas e experiências, os cidadãos percebem as instituições como algo diferente, senão oposto, àquilo para o qual existem: neste caso, a indiferença ou a ineficiência institucional diante de demandas sociais, corrupção, fraude ou desrespeito de direitos de cidadania geram suspeição, descrédito e desesperança, comprometendo a aquiescência, a obediência e a submissão dos cidadãos à lei e às estruturas que regulam a vida social (LEVI, 1998; MILLER e LISTHAUG, 1999; DALTON, 1999; TYLER, 1998). 
Democracias capazes de sustentar ciclos continuados de desenvolvimento econômico e social convivem, em boa parte dos casos, com processos permanentes de qualificação cognitiva de seus cidadãos em conseqüência de transformações culturais e isso estimula alguma desconfiança dos segmentos mais bem informados, traduzindo atitude crítica face ao seu desempenho (NORRIS, 1999; INGLEHART, 1999; KLINGEMANN e FUCHS, 1995; NYE et al., 1997; PHARR e PUTNAM, 2000). Mas a desconfiança generalizada e continuada nas instituições públicas fundamentais, no caso de democracias que ainda enfrentam o desafio de enraizar a sua justificação ético-política nos hábitos e nas condutas dos cidadãos, pode evidenciar dificuldades de funcionamento do regime, ao comprometer ações de coordenação, de cooperação e de solidariedade social (GIDDENS, 1989; OFFE, 1999; NEWTON e NORRIS, 2000).

Isso é assim porque, na democracia, as instituições cumprem pelo menos duas funções complementares: a primeira envolve a distribuição do poder de tomar decisões que afetam a coletividade; a segunda assegura a participação dos cidadãos na avaliação e no julgamento que fundamenta o processo de tomada dessas decisões. Por um lado, trata-se de controlar o poder para que não tolha a liberdade dos cidadãos ou distorça os objetivos da vida pública; por outro, trata-se de assegurar que, como membros da comunidade política, os cidadãos possam transformar suas demandas, aspirações, interesses e preferências em políticas a serem adotadas pelo poder público. Isso supõe regras, normas, mecanismos e processos institucionais associados a valores cuja função é realizar uma das principais promessas democráticas, isto é, a igualdade dos cidadãos perante a lei (SARTORI, 1965; DAHL, 1989; BOBBIO, 1984). Entre os mecanismos que asseguram isso está o direito de escolher governos, só plenamente democrático quando todos os membros adultos da comunidade política afetados por decisões coletivas têm direito de influir na vida política através do voto ${ }^{1}$. Mas o voto per se não garante que o que os cidadãos aspiram para si e para a coletividade se realize; cabe às instituições de representação, de justiça, de decisão e implementação de políticas públicas assegurar a distribuição de poder e, ao mesmo tempo, garantir que entre o julgamento dos cidadãos a respeito das prioridades públicas e o processo de tomada de decisões correspondente haja uma ligação. Isso é o que torna as instituições um aspecto fundamental do regime democrático, sem o qual o seu funcionamento é falho (HADENIUS, 2001).

\footnotetext{
${ }^{1}$ Nas democracias modernas, estão excluídas dessa totalidade as crianças e os jovens, até certo limite de idade. Os idosos, após certa idade, podem escolher se querem continuar beneficiando-se do direito de voto.
} 
Este artigo examina os fundamentos da convivência contraditória entre a desconfiança dos cidadãos nas instituições públicas e seu apoio à democracia e propõe um modelo para a sua análise. A primeira seção descreve brevemente o contexto político em que o problema da desconfiança se situa no Brasil; as demais seções abordam o tratamento dado pela literatura aos conceitos de confiança social e confiança política e, depois de discutir alguns aspectos conceituais e metodológicos decorrentes da experiência de pesquisa, o texto contrasta os diferentes modelos de análise do tema e explicita a alternativa considerada mais adequada para o seu tratamento.

\section{Um paradoxo brasileiro}

Existe certo truísmo na literatura sobre o desenvolvimento político brasileiro em torno da idéia de que o país alterna, pelo menos desde o advento da República, ciclos autoritários com ciclos democráticos (SILVA, 1981; SKIDMORE, 1969); e, se se tomar como base as mudanças políticas introduzidas a partir da Revolução de 1930, verifica-se que o país viveu, desde então, pelo menos três períodos históricos em que a vigência de um regime democrático, após o final da $2^{a}$ Guerra Mundial, foi precedida e sucedida por regimes autoritários, o de 1937 e o de 1964. Isso pareceria indicar que a história recente confirma aquele truísmo, sugerindo que a implantação de um regime democrático no Brasil, em bases sólidas e permanentes, é uma possibilidade de difícil realização.

Contudo, desenvolvimentos recentes indicam que o país pode ter ingressado desde 1985 em um ciclo virtuoso que está permitindo romper com aquele padrão prevalecente entre 1946 e 1964, quando conflitos políticos normais da vida democrática assumiram freqüentemente a feição de antagonismos inconciliáveis entre as forças políticas, gerando, além de paralisia decisória, tensões permanentes entre o executivo e o legislativo - tensões arbitradas, diversas vezes, pela intervenção inconstitucional dos militares na vida pública (D'ARAUJO et al., 1994; SANTOS, 1986). Em sua fase atual, as instituições democráticas têm funcionado com relativa harmonia e, mais importante, com continuidade no tempo, seguindo certo padrão incremental de desenvolvimento. As forças armadas recolheram-se às suas funções constitucionais e o impeachment de um presidente da república, em 1992, por decisão do poder legislativo, intervindo no funcionamento do executivo, não levou a nenhuma quebra da normalidade institucional, exemplificando o padrão que pode estar se consolidando no país. Ademais, alguns anos depois, outro processo envolvendo a avaliação de conduta de autoridades públicas - no caso, de parlamentares que integravam a Comissão de Orçamento do Congresso Nacional - foi aberto e concluído com a adoção das 
punições previstas em lei, sem que isso tivesse representado ameaça ao funcionamento das instituições democráticas. Além disso, nos dois períodos seguintes, a sucessão presidencial deu-se de acordo com as regras constitucionais e, por quase uma década, as instituições têm funcionado em um quadro de cooperação e de harmonia relativa; nem mesmo o uso às vezes excessivo do recurso às medidas provisórias pelo executivo ameaçou essa harmonia (GRAEFF, 2000; CHAGAS, 2002).

Apesar da possibilidade de emergência de um novo regime autoritário não poder ser excluída de forma definitiva, não existem no horizonte político - no atual momento histórico - nem as condições de crise usualmente associadas a essa possibilidade nem alternativas políticas comprometidas com aquele objetivo excepcional. Ao contrário, desde 1985, a maioria quase absoluta dos atores políticos comporta-se tendo a democracia como referência de sua ação e, diferentemente de outros períodos históricos, os ciclos eleitorais sucedem-se com regularidade, permitindo que os cidadãos escolham livremente os governantes do país dentre lideranças apresentadas pelos partidos políticos; ademais, embora a participação em eleições seja obrigação definida por lei, a taxa de votos válidos nas últimas quatro eleições majoritárias estabilizou-se em patamar bastante significativo, indicando que essa prática da democracia ocupa lugar importante na cultura política dos brasileiros.

Tais condições permitiram que o país experimentasse, na eleição presidencial de 2002, um dos mais importantes processos de alternância no governo desde o surgimento da República. Pela primeira vez no período republicano, os eleitores brasileiros colocaram à frente do Estado, não apenas um partido de oposição à aliança de forças que governava o país desde o início do atual período democrático, mas que reivindicava uma orientação anti-establishment. Com efeito, após dois períodos presidenciais marcados por significativos avanços no sentido de reorganização e de estabilização da economia - a exemplo da abertura comercial, do controle da inflação e da retomada do crescimento econômico, com tímidos mas efetivos efeitos sociais ${ }^{2}$-, os eleitores brasileiros optaram por uma alternativa de mudança que, além da troca de liderança à frente do Estado, deu origem a novas expectativas quanto ao papel do governo e das instituições democráticas.

\footnotetext{
2 De meados dos anos 1980 até a data de lançamento do Plano Real, em junho de 1994, o Brasil conheceu uma inflação média de $1.110 \%$ ao ano; entre meados de 1994 e meados de 2002, a média anual da inflação esteve em torno de 15\%; por outra parte, entre 1981 e 1992, a taxa de expansão do PIB brasileiro passou de uma média de 1,4\% ao ano para 3,5\% entre 1993 e 1998; essa média caiu, em 1999, sob o impacto da desvalorização do Real e da crise financeira internacional, e voltou a crescer, em 2001 e 2002, embora timidamente (GRAEFF, 2000). Quanto aos efeitos sociais dessas mudanças, eles dizem respeito às quedas do analfabetismo e da mortalidade infantil e ao aumento das taxas de inclusão dos mais pobres no sistema educacional.
} 
Embora índices semelhantes oscilem ao sabor de mudanças conjunturais, o novo governo contou inicialmente com significativo apoio da opinião pública e valeuse deste apoio para estimular, entre outras coisas, o surgimento de novas expectativas quanto ao papel das instituições democráticas. Exemplo disso foram as reformas previdenciária e tributária que, incidindo sobre serviços públicos de grande impacto social, acenaram com a possibilidade de funcionamento mais eficaz e mais justo ${ }^{3}$; por outra parte, mesmo alimentando controvérsias sobre o papel dos outros poderes republicanos, o executivo mostrou interesse também em mobilizar a opinião pública em torno dos problemas de funcionamento da justiça, estimulando a percepção dos cidadãos de que, também nessa área, mudanças são necessárias para que governos e instituições democráticas funcionem em consonância com os seus próprios objetivos.

O cenário descrito contrasta com o quadro de desconfiança nas instituições democráticas e, ainda que este artigo não pretenda realizar uma análise empírica do caso brasileiro, o contexto descrito mostra a importância de se ampliar o conhecimento em torno do fenômeno da confiança e da desconfiança.

\section{A confiança social}

O conceito de confiança ${ }^{4}$ ganhou uso bastante amplo nas ciências humanas nas últimas décadas, tendo autores de diferentes escolas de pensamento chamado a atenção, em primeiro lugar, para a natureza relacional do fenômeno cujos efeitos dependeriam, segundo alguns, do contexto de cultura e valores em que estão situados os que se utilizam dela e, segundo outros, da natureza racional de sua motivação. Assim, a noção de confiança tem sido utilizada para designar uma grande variedade de fenômenos sociais e políticos que, malgrado colocar os atores envolvidos em situação de risco em sua relação com os outros - como no caso da incerteza envolvida em situações que supõem a solução de problemas de ação coletiva ou que incluem a suposição convencional sobre o auto-interesse dos atores -, refere-se à coesão social considerada indispensável ao funcionamento das sociedades modernas, complexas e diferenciadas. Isto levou alguns autores a

\footnotetext{
${ }^{3}$ Em 4/5/2003, o jornal O Estado de S. Paulo divulgou os resultados de uma pesquisa encomendada pela CNI segundo os quais cerca de $2 / 3$ dos eleitores aprovavam as propostas de reformas previdenciária e tributária do governo e esperavam que elas trouxessem mais eqüidade e justiça em conseqüência de correções que se esperava que fossem introduzidas no funcionamento daquelas instituições.

4 Segundo o "Novo Aurélio - Dicionário da Língua Portuguesa", o substantivo "confiança" refere-se à "segurança íntima de procedimento, crédito, fé" e, mais importante, à "segurança e bom conceito que inspiram as pessoas de probidade, talento, discrição, etc." (Rio de Janeiro, Ed. Nova Fronteira, 1999, p. 525).
} 
designarem-na de fraternidade para distinguí-la de e, ao mesmo tempo, situá-la em relação às dimensões da liberdade e da igualdade (LUHMANN, 1979; NEWTON, 1999; WARREN, 1999).

Em sua origem, as pesquisas sobre confiança desenvolveram-se inicialmente no campo da psicologia social, a qual associou a chamada confiança interpessoal generalizada a traços de personalidade dos indivíduos, a exemplo de tendências misantrópicas ou de disposição para o convívio social; as influências básicas formadoras do processo de individuação, como a relação mãe-filhos, foram vistas como fundamentais para gerar e consolidar atitudes de confiança (mais a respeito na última seção). Depois, a adoção do conceito por outras disciplinas levou à diversificação de definições, a exemplo de correntes sociológicas para as quais a confiança interpessoal passou a ser vista como fator propulsor de ciclos virtuosos de desenvolvimento social e econômico (FUKUYAMA, 1995). Na análise política, em particular, o conceito tem sido utilizado tanto pelas teorias de cultura política (ALMOND e VERBA, 1963) como de capital social (PUTNAM, 1993) para enfatizar a sua influência para a consolidação e a estabilidade do regime democrático. O fato de as pessoas confiarem umas nas outras - e, dessa forma, também em autoridades e em lideranças políticas - funcionaria como um elemento facilitador para que os membros da comunidade política ou de grupos específicos adotassem formas de ação comum capazes de gerar, no primeiro caso, virtude cívica reforçadora do sistema democrático e, no segundo, a acumulação de experiência necessária à produção de benefícios particulares esperados pelos grupos envolvidos (SZTOMPKA, 1999; SELIGMAN, 1997).

Segundo uma definição bastante usual, mesmo supondo um componente associado por alguns a um ato de "fé" (ROSENBERG, 1956), o fenômeno da confiança envolveria fundamentalmente a expectativa racional de A (o confiante) em relação às ações ou curso de ações adotados ou a serem adotados por B (o confiado). Mas, em vista da imprevisibilidade da natureza humana, isto é, do fato de o comportamento do outro (em relação ao qual está situado o ator confiante) não poder ser controlado de modo completo e absoluto - a não ser em situações-limite -, a situação implicaria quase sempre em risco de dano ou, quando menos, de vulnerabilidade de A diante de B. Com efeito, uma vez que o ato de confiar é insuficiente per se para determinar o resultado da interação, se a relação de confiança entre os indivíduos deixar de incluir o que defensores da escola da escolha racional designaram como encapsulamento de interesses das partes envolvidas, o abuso da confiança seria inevitável. O encapsulamento de interesses implica, nessa perspectiva, que o confiante conheça a motivação do confiado, de modo que possa saber por antecipação se os seus interesses serão levados em consideração pelo último, cujas motivações próprias também supõem que seus interesses sejam contemplados pela ação adotada pelo primeiro. Nessa acepção, a 
confiança seria uma aposta baseada na crença de que os interesses mútuos dos atores envolvidos são condição suficiente para gerar benefícios comuns e, assim, inocular a possibilidade de dano decorrente de seu abuso (HARDIN, 1999; LEVI, 1999).

Outros autores sugeriram, de modo alternativo, que a confiança corresponde a uma variável de raiz sociocultural, de implicações normativas e que a sua escolha não é sempre racional, nem se determina - como seria de se esperar no caso de uma decisão baseada em cálculo estrito de custos/benefícios - pelo montante de informação disponível a respeito do comportamento dos outros. A abordagem estritamente racional do fenômeno da confiança esbarraria no fato de os indivíduos terem capacidade cognitiva limitada para acessar, na quantidade e na qualidade necessárias, as informações a respeito da conduta dos outros ou para avaliar adequadamente a utilidade da interação em que se envolveriam (KRAMER, 1999). Argumentou-se que valores sociais - como o republicanismo cívico, a solidariedade social, o desejo de reconhecimento, o altruísmo, etc. - podem formar a base da decisão de confiar quando os atores situam-se em contextos que incluem insuficiente ou nenhum mecanismo de controle sobre o comportamento dos outros.

A forma mais usual da confiança expressar-se é como fenômeno particularizado, ou seja, relativo à experiência interpessoal de indivíduos pertencentes a grupos ou comunidades específicas como famílias, etnias, religiões, agregações ecológicas ou associações profissionais, entre outros, quando a comunicação face a face induz os participantes a assimilarem normas de cooperação e de reciprocidade que funcionam como elementos de contenção dos riscos de abuso da confiança; em última análise, a interação entre atores que têm familiaridade com os seus pares - e que, portanto, têm memória cognitiva de seu comportamento - faria do ato de confiar quase uma decorrência natural da experiência em comum. Nesse caso, a confiança funcionaria como um elemento de reiteração dos particularismos característicos dos grupos ou comunidades referidos por ela, razão pela qual parte da literatura descartou a influência desse tipo de confiança para a ocorrência de eventos como a cooperação social ou a implementação de objetivos políticos coletivos (USLANER, 2002).

O fenômeno assume maior relevância ao se manifestar nas sociedades modernas, complexas e diferenciadas de forma generalizada. Neste caso, a confiança social estende os seus efeitos não apenas a amigos ou conhecidos integrantes de grupos específicos, mas a estranhos que, na condição de cidadãos, integram a comunidade política. Confiar em estranhos, em quem é diferente ou em pessoas com quem não se tem familiaridade, implica em disposição potencial para agir e cooperar com vistas a objetivos coletivos, cuja definição extrapola o estrito terreno do interesse individual dos envolvidos. A confiança funciona, neste caso, como uma alternativa para indivíduos que se sentem vulneráveis em face de sua 
inserção em contextos de crescente complexidade e interdependência típicos das sociedades modernas, mas que, ao mesmo tempo, compartilham uma perspectiva comum definida por sua condição de cidadãos. Como não podem controlar individualmente os fatores que influenciam ou definem a sua vulnerabilidade, nem se informar completamente sobre as circunstâncias que a produzem, eles usam a confiança como recurso facilitador da coordenação de ações que são indispensáveis para a realização de objetivos sociais de amplo alcance e que são relativos aos direitos de cidadania. Assim, a confiança social operaria como um redutor da complexidade das escolhas individuais condicionadas pela incerteza que caracteriza a vida moderna e, ao mesmo tempo, ofereceria um marco de segurança para atores que, necessitando definir o horizonte em que estão situadas as relações de que dependem - dentre as quais, as relações de poder -, querem aumentar o grau de confiabilidade de sua própria ação (LUHMANN, 1979; GIDDENS, 1990).

Adotando essa perspectiva, tanto defensores da escola culturalista como autores de orientação eclética identificaram entre as fontes potenciais da confiança social fatores relativos a valores e fundamentos ético-políticos, o capital social e a capacidade de cooperação altruísta dos que se utilizam dela (USLANER, 2002; BRAITHWAITE, 1998; PUTNAM, 2000). Assim, Uslaner, por exemplo, sustentou que a confiança tem raízes em fundamentos morais, baseados em concepções acerca da natureza humana, que se expressariam como valores sociais ligados à experiência coletiva de seus participantes, a exemplo da associação entre otimismo diante da vida e distribuição de riqueza na sociedade: mais otimismo e mais distribuição de riqueza gerariam mais confiança. Robert Putnam, por outro lado, argumentou que a confiança decorre especialmente da existência de formas de associação social e cívica, repertórios coletivos, normas e redes facilitadoras de coordenação social que formariam o capital social indispensável para a existência de uma interação social robusta e, ao mesmo tempo, propiciadora de desenvolvimento econômico e político. A confiança seria um bem público cujo valor variaria de acordo com a intensidade e a adequação do seu uso: o aumento relativo da confiança, resultante de sua progressiva e crescente utilização, estimularia a formação de círculos virtuosos - ou, na sua ausência, viciosos - responsáveis pelo progresso social e econômico. A confiança é vista como propulsora do capital social, mas a literatura associada a essa abordagem também sugeriu que este é que ajuda a criar o ambiente necessário ao surgimento daquela (PUTNAM, 1993).

Chamando a atenção para a circularidade desse argumento, os críticos dessa concepção mostraram, no entanto, que a noção de capital social vista de modo estrito como uma espécie de função de redes de associação voluntária, organizadas na esfera da sociedade civil, não é suficiente para explicar a origem da confiança; com efeito, não é fácil demonstrar que qualquer forma de associativismo baste para gerar confiança e, menos ainda, virtude cívica. Por isso, argumentou-se 
que para avançar o conhecimento da questão é necessário examinar a relação entre o compromisso moral em que se baseia a comunidade política, as condições de emergência da sociedade civil e o complexo de normas e regras que estruturam as instituições da esfera pública. A confiança decorreria do modo como esses fatores se articulam e não, simplesmente, da existência ou não do capital social (COHEN, 1999).

\section{A confiança política}

Definida originalmente como fenômeno de natureza interpessoal, a confiança política ou em instituições políticas suscita dúvidas quanto à sua aplicabilidade a situações que não envolvem estritamente relações entre pessoas, mas entre estas e entes inanimados como as instituições. Autores da escola da escolha racional sustentaram que não faz sentido falar em confiança em instituições porque quem confia ou se dispõe a fazê-lo não tem como conhecer os interesses e as motivações dos indivíduos que as dirigem ou animam - seja por causa da distância existente nas sociedades complexas entre os cidadãos e as estruturas de poder, seja ainda porque os primeiros não têm meios de inteirar-se adequadamente a respeito das motivações de tantos e desconhecidos indivíduos que se ocupam da administração das segundas (HARDIN, 1999). Os críticos desta perspectiva argumentaram que a confiança importa para o funcionamento das instituições porque suas regras constitutivas remetem necessariamente aos conteúdos normativos tomados como referência pelos cidadãos em seu relacionamento com as estruturas da comunidade política a que pertencem; dessa forma, as instituições não seriam neutras mas, antes, mecanismos de mediação informados por valores relativos aos objetivos coletivos a que se propõem realizar (PETTIT, 1998; OFFE, 1999; WARREN, 1999).

A idéia é que as regras constitutivas das instituições, especialmente as relativas à sua justificação, geram expectativas sociais a respeito de seu desempenho, assim como dos responsáveis por sua administração, e isto se reflete na articulação de papéis a eles atribuídos por aquelas regras. A confiança em instituições estaria baseada no fato de os cidadãos compartilharem uma perspectiva comum relativa ao seu pertencimento à comunidade política, uma circunstância implícita na justificação normativa das instituições. Por outro lado, isso ofereceria os fundamentos a partir dos quais os papéis desempenhados pelos responsáveis pelas instituições são estabelecidos. Nessas condições, os julgamentos dos cidadãos para decidir confiar em instituições referem-se à performance destas mas, ao mesmo tempo, tomam por base a avaliação da consistência e da coerência internas de suas normas, mais do que as avaliações estritas do comportamento individual dos seus gestores e administradores. Os 
ordenamentos normativos atribuem sentido e atualizam o comportamento destes e constituem assim a base das avaliações e das atitudes dos cidadãos (WARREN, 1999). Por essa razão, alguns autores sustentaram que a confiança em instituições deve ser vista como um caso especial da confiança em pessoas, ou seja, um equivalente funcional da confiança interpessoal (HARRÉ, 1999; COHEN, 1999).

Esse esquema conceitual supõe a aceitação e, ao mesmo tempo, a identificação dos cidadãos com os princípios éticos e normativos que constituem as instituições, algo relacionado com o seu compromisso moral com a associação ou a comunidade política a que pertencem (MOUFFE, 1992; STOKES, 2002). Em última análise, a razão para se confiar nas instituições estaria no fato de elas serem definidas por lei, ou seja, pela condição de legitimidade da própria comunidade política. A confiança dos cidadãos fundar-se-ia, assim, na idéia normativa da lei que fundamenta as instituições e que, ao mesmo tempo, autoriza as expectativas sociais a respeito do seu funcionamento mediado pelo comportamento de seus gestores. Como esse comportamento também é previsto legalmente, isso justificaria que a quebra de regras de funcionamento das instituições fosse vista como passível de sanções (LEVI, 1998).

\section{Confiança e legitimidade}

Essa abordagem da confiança retoma a questão da legitimidade política. A sociologia política de Max Weber segue sendo, nesse sentido, uma referência importante ao distinguir entre as dimensões de poder e de autoridade e ao advogar a superioridade da última para tratar da natureza da coesão social da comunidade política. Enquanto no caso da autoridade a relação dos cidadãos - assim como do pessoal burocrático e administrativo do Estado - com governantes e autoridades públicas seria motivada por aquiescência voluntária, isto é, por adesão de natureza não-coercitiva, no caso do poder a relação envolveria, em seu limite, o uso da força, embora regulado por lei. A questão, então, estaria em saber o motivo da aquiescência dos cidadãos às autoridades públicas e às instituições políticas. Weber respondeu a essa questão propondo a sua famosa tipologia tripartite da legitimidade: o primeiro tipo refere-se à aceitação da autoridade motivada pelo respeito à tradição, embora as sociedades que se modernizaram ou estão em vias de concluir esse processo não possam ser incluídas aí; o segundo tipo alude às qualidades carismáticas atribuídas a certas lideranças políticas ou a certas idéias expressas por elas mas, claramente, isso constitui um caso especial; quanto ao terceiro tipo, a aquiescência depende de sua ordenação racional-legal, ou seja, os cidadãos conformam-se e manifestam respeito a autoridades e a instituições constituídas e definidas por regras legais e racionais. 
Essa perspectiva orientou parte significativa da literatura sobre o tema ao distinguir entre estruturas políticas legítimas e ilegítimas a partir da existência de preceitos constitucionais originados de consenso normativo negociado pelas forças políticas - algo que prevê a participação dos cidadãos na vida pública através da regra da maioria para a escolha de governantes e para a tomada de decisões vinculantes; dos direitos civis, políticos e sociais, entre os quais, os que asseguram a liberdade de expressão de minorias; do direito de articulação e representação de interesses e do princípio de controle público da ação de governantes através de eleições regulares e freqüentes (accountability); e, finalmente, de mecanismos de mútuo controle entre os poderes públicos (BOBBIO, 1984; DAHL, 1956). Esses aspectos constituiriam os fundamentos a partir dos quais os cidadãos participariam de processos de tomada de decisões vinculantes para eles como membros da comunidade política através da competição pela realização de suas aspirações e interesses. Conflito e cooperação, como dimensões constitutivas do processo, dependeriam de um fluxo permanente de formação e reconstrução; isso é o que estaria na base da orientação avaliativa dos cidadãos em face de autoridades e de instituições, e essa avaliação envolveria a percepção de como e quanto governos e instituições são capazes de responder às expectativas normativas geradas pela ordem institucional e pelos processos eleitorais (ALMOND e VERBA, 1963; STOKES, 1962; MILLER, 1974).

A formulação corresponde às condições associadas ao advento da modernidade mas, mesmo em Weber, não fica inteiramente claro se os cidadãos e os funcionários do Estado obedecem e submetem-se a ordens e regras de autoridades e instituições simplesmente porque elas correspondem a procedimentos que são legítimos, isto é, racional e legalmente corretos. Com efeito, como leis e normas não são auto-executáveis nem auto-impositivas, a aquiescência e a submissão que implicam têm de depender de algum outro fator que a teoria precisaria explicar melhor. A questão ocupou parte considerável dos esforços de pesquisas que, a partir de meados do século $\mathrm{XX}$, tentaram explicar a questão da confiança política, mas o consenso alcançado a respeito é limitado, como se verá nas seções seguintes. 


\section{A controvérsia do apoio político}

A tradição de pesquisa empírica sobre a importância do fenômeno da confiança política para o funcionamento do regime democrático estabeleceu suas bases a partir de 1948, quando alguns itens sobre o tema foram incluídos em questionários de surveys de opinião, atitudes e comportamento políticos aplicados na Alemanha Ocidental. Mais tarde, em 1958, foram introduzidos e ampliados nos Estados Unidos e, em 1968, repetidos na Suécia, mas os trabalhos mais importantes na área resultaram de iniciativas de pesquisadores da Universidade de Michigan que partiram da suposição de que atitudes e opiniões individuais são elos importantes entre as dimensões micro e macro da política. Eles postularam que os instrumentos de mensuração empírica do fenômeno deveriam ter em conta que os cidadãos combinam, embora não necessariamente de forma semelhante ou equilibrada, critérios normativos e racionais relativos à probidade, sentido de justiça e eficácia da ação dos atores correspondentes para avaliar e julgar governos, governantes e instituições políticas (STOKES, 1962; HETHERINGTON, 1998) ${ }^{5}$.

Resultados promissores desse esforço inicial não impediram que, mesmo com a sólida reputação adquirida por esses estudos a partir dos anos 1970, o uso do conceito fosse questionado com base no argumento de que se referia, indistintamente, tanto às qualidades intrínsecas do sistema político (legitimidade), como aos atributos da performance de lideranças políticas e de governantes (efetividade), embaralhando, ao invés de discriminar, dimensões empíricas diferentes que, por causa de sua natureza complexa, exigiam um tratamento mais cuidadoso de suas especificidades para gerar conhecimento novo. A confusão entre os conceitos de confiança, apoio a políticos e apoio a governos pouco ajudou a esclarecer a natureza da adesão dos cidadãos ao regime político e se efetivamente a confiança é importante para isso.

Embora parecesse o contrário, a controvérsia não dizia respeito apenas a uma questão empírica. Nos termos da análise do sistema político formulada anos antes por Easton (1965), ao questionar se os instrumentos de mensuração de confiança política per se correlacionavam-se somente com a dimensão de apoio político específico, isto é, apoio a governos e a elites governantes, deixando à margem aquela de apoio político difuso, relativa ao sistema político como um todo, o debate mostrou que a questão de fundo dizia respeito a como e quanto a confiança política reforçava a relação dos cidadãos com diferentes dimensões empíricas como governos, lideranças políticas e as estruturas políticas a que pertenciam. O resultado da controvérsia levou a um maior refinamento dos

\footnotetext{
${ }^{5}$ Hetherington (1998) lista os principais itens incluídos nos questionários originais de Michigan para atender aos critérios mencionados.
} 
instrumentos de mensuração do fenômeno e, mais importante, à exigência de que o conceito levasse em conta a natureza multidimensional da confiança política (CITRIN, 1974; MILLER, 1974).

Os novos estudos do tema incorporaram esses avanços ao insistir na existência de uma conexão fundamental entre a confiança política e a aceitação do regime, mas sugerindo que, para além de sua eventual ocorrência em pontos no tempo, a existência de níveis contínuos de desconfiança ameaça a estabilidade desse regime (LIPSET e SCHNEIDER, 1983; WILLIAMS, 1985). A classificação eastoniana foi reelaborada para dar conta da multidimensionalidade do fenômeno, distinguindo entre o apoio para a comunidade política, para o regime e para sua performance, por um lado, e aquele dirigido ao governo do dia, suas autoridades e a lideranças políticas, por outro. Tornou-se evidente que não se tratava de relação automática entre uma e outra dimensão, sem distinção entre elas, mas de detectar a natureza da dinâmica de seu relacionamento. Uma vez que governos podem ser vistos por entrevistados de pesquisas de opinião como expressão de lideranças políticas específicas ou, alternativamente, como estruturas de poder e ainda como instituições operadas por autoridades eleitas pelos cidadãos ou por seus delegados, ficou evidente que era necessário distinguir analiticamente entre os sentimentos e atitudes dos cidadãos relativos a essas dimensões e, em conseqüência, criar instrumentos de mensuração capazes de dar conta dessas diferenças.

Mesmo tendo sido útil para mapear um problema que exigia maior acuidade em sua definição conceitual e na escolha dos instrumentos de sua mensuração, a controvérsia deixou algumas questões sem solução. Assim, mesmo que produtivo para ampliar o conhecimento de diferentes fatores que influenciam a confiança dos cidadãos, o debate correspondente revelou-se insuficiente para esclarecer os efeitos que ela provoca a curto, médio e longo prazos para o funcionamento do sistema político: a ausência de confiança política bloqueia o regime? Impede a sua possibilidade de coordenar ações necessárias ao atendimento de demandas públicas? Coube aos estudos seguintes colocar essas questões no centro da preocupação dos diferentes modelos propostos para explicar a confiança política. A sua apresentação, a seguir, completa o quadro em cujo contexto o tema tem sido tratado. 


\section{Modelos de explicação}

Uma ampla e extensa literatura documentou, a partir dos anos 1980, o fenômeno da desconfiança política em várias partes do mundo e, mais recentemente, nas democracias surgidas na chamada terceira onda de democratização (HUNTINGTON, 1991). Os estudos comparativos apontaram para a grande variação do fenômeno: em democracias consolidadas a partir de meados do século passado, como os casos do Japão, Itália e, em menor grau, Alemanha, o cinismo mostrou-se endêmico, generalizado e enraizado na sociedade; em outras, cuja estabilidade e duração no tempo é mais longa, como Holanda, Noruega e Dinamarca, a confiança nas instituições democráticas apresenta índices elevados, estáveis e crescentes com o passar do tempo. A variação mais dramática, contudo, refere-se a casos de democracias há muito estabelecidas, como Estados Unidos, Inglaterra, França, Suécia e Canadá, países onde a existência de pesquisa continuada por mais de quatro décadas mostrou que os índices de confiança nas autoridades e nas instituições caíram sistematicamente nos últimos trinta anos, invertendo tendências dominantes nos anos 1960, quando, como em alguns casos, mais de 3/4 dos cidadãos expressavam confiança em governos e instituições em contraposição a cerca de 25\% na atualidade (KLINGEMANN, 1999; NEWTON e NORRIS, 2000; DALTON, 1999).

O caso das novas democracias oferece um panorama distinto e merece um esforço analítico e explicativo próprio: enquanto em vários países do Leste Europeu a avaliação dos novos regimes democráticos mostrou-se, no início dos anos 1990, bastante modesta, raramente ultrapassando os índices favoráveis obtidos anteriormente pelos regimes que os antecederam (MISHLER e ROSE, 1999), em dezessete países latino-americanos pesquisados pelo Latinobarómetro, a partir de meados dos anos 1990, apenas $1 / 5$ do público expressou "muita" ou "alguma" confiança em partidos políticos, e menos de 1/3 declarou confiar nos governos, parlamentos nacionais, nos funcionários públicos, na polícia e no judiciário (LAGOS, 1997). Estudos de casos individuais como do México confirmaram esses resultados (DURAND PONTE, 2004). O panorama geral das novas democracias mostra, dessa forma, que nesse caso não está em questão uma crise de confiança política que, em realidade, não logrou se enraizar em sua experiência recente, mas as dificuldades do novo regime para adensar a ligação orgânica entre os cidadãos e as estruturas de poder. Na maior parte dos casos, as pessoas revelam não confiar umas nas outras e apenas um pouco mais nas instituições. Se isso não impede a existência do regime democrático, aponta, contudo, para problemas que podem comprometer sua capacidade de coordenar ações coletivas. Quando as instituições não contam com a confiança dos cidadãos, têm dificuldades para funcionar como mediação 
entre suas expectativas e os objetivos coletivos propostos por governos e por lideranças políticas (OFFE, 1999).

Como explicar, então, tantas diferenças entre os países? Por que em alguns casos os cidadãos passaram a desconfiar tanto de autoridades e de instituições políticas após anos de aquiescência e de consentimento ao sistema político a que pertencem? E quais os efeitos, no caso das novas democracias, do fato das instituições de mediação serem tão pouco acreditadas? Quais as raízes permanentes do fenômeno? Diferentes modelos propõem-se a explicar a erosão da confiança dos cidadãos nas instituições públicas, mas eles dividem os analistas em relação a vários aspectos tratados neste artigo. Sumariados a partir de sua centralidade para a literatura pertinente, os modelos examinados a seguir ajudam a explicitar a orientação adotada neste artigo para a análise do tema.

Teorias sócio-psicológicas - Essa perspectiva explica o fenômeno da confiança política em função dos tipos de personalidade dos indivíduos. Atitudes e sentimentos de confiança em si próprio e nos outros, assim como otimismo ou pessimismo diante da vida são vistos como decorrentes de traços adquiridos nos primeiros estágios de desenvolvimento psicológico das pessoas, um processo determinado, em grande parte, pela relação primária mãe-filhos; essa matriz de formação da personalidade explicaria os comportamentos e atitudes individuais permanentes (ALLPORT, 1961; CATTELL, 1965). Assim, em decorrência de sua história psicológica, alguns indivíduos teriam uma visão positiva da vida e, em conseqüência, seriam mais predispostos ou propensos a cooperar e a confiar nos outros; outros, marcados por uma visão negativa da vida, mostrar-se-iam incapazes de depositar confiança no mundo exterior, revelando, na maior parte das vezes, cautela, distanciamento e desconfiança em face de estranhos, inclusive, autoridades e funcionários de governos com os quais não têm contato direto; misantropia e desconfiança seriam faces diferentes da mesma atitude (ROSENBERG, 1957). A confiança corresponderia, assim, a uma orientação afetiva decorrente da personalidade básica dos indivíduos, algo independente de sua experiência exterior, a exemplo da interação envolvida pela participação na vida pública. Essa concepção serviu de base para a distinção adotada por parte da literatura especializada entre indivíduos confiantes e cínicos (GABRIEL, 1995), cuja aproximação ou afastamento da política e de suas instituições pouco ou nada dependeria da presença de valores sociais ou do desempenho de governantes e instituições públicas. 
Vários limites podem ser apontados em relação a essa perspectiva: por um lado, referem-se ao fato de ela querer explicar mudanças em orientações gerais de conjuntos inteiros de populações dos países somente a partir de traços psicológicos de indivíduos e, ainda que outras explicações do fenômeno também recorram a interpretações de respostas individuais da questão, os resultados obtidos ajudam a conhecer mais a respeito de casos individuais do que do comportamento de agregados coletivos integrados por eles. Com efeito, os estudos apoiados nessa concepção concentraram-se, preferencialmente, na identificação de tipos como confiantes, cínicos ou alienados, e não nas circunstâncias sociais ou políticas que permitiriam associar sua emergência à dimensão macropolítica a que se referem. Por outro lado, a teoria também não explica os casos em que indivíduos pertencentes à mesma família - e, assim, condicionados por influência primária semelhante - apresentam orientações divergentes no que se refere a aspectos da vida política.

Por outra parte, admitindo-se que a confiança seja, de fato, um traço do caráter dos indivíduos, seria de se esperar uma associação consistente entre confiança social e confiança política, mas isso encontrou pouca sustentação em pesquisas que mostraram que as pessoas expressam diferentes formas de confiabilidade, as quais são independentes entre si, ou seja, os indivíduos que confiam uns nos outros ou em organizações sociais não apresentam, necessariamente, sinais de confiança em políticos ou em instituições públicas (NEWTON e NORRIS, 2000).

Teorias socioculturais - Partindo da trilha aberta por Almond e Verba nos anos 1960, essa perspectiva explica a variação do fenômeno de confiança política entre nações a partir do complexo de valores culturais de cada sociedade. As idéias fundadoras das sociedades seriam expressas na cultura política e marcariam as concepções dos indivíduos a respeito de governos, autoridades e instituições políticas. Valores transmitidos através de processos de socialização corresponderiam aos de grupos básicos como família, amigos, escola e grupos religiosos. A abordagem tem raízes no pensamento de autores como Alexis de Tocqueville e John Stuart Mill, para os quais a arte de associar-se e de integrar-se em instituições intermediárias são meios dos cidadãos treinarem e educarem a sua competência para a vida cívica. Ao valorizar a participação dos indivíduos em associações voluntárias, qualificando-os para a realização de objetivos comuns através da criação de ambiente social favorável ao desenvolvimento da confiança entre os membros das associações, e deles com autoridades e instituições políticas, as teorias do capital social reatualizaram a importância dessa abordagem (FUKUYAMA, 1995; PUTNAM, 1993). Sua influência na literatura contemporânea é significativa, como atestam as concepções sobre a capacidade da sociedade 
inculcar nos indivíduos "hábitos do coração" como confiança, reciprocidade, solidariedade e cooperação social (BELLAH et al., 1985); como mostram as perspectivas que revalorizam as virtudes de ativação da sociedade civil para gerar relações sociais de cooperação (COLEMAN, 1990; INGLEHART e ABRAMSON, 1994; SZTOMPKA, 1996); ou como sugerem as que associam a confiança social com a existência de cultura cívica capaz de assegurar a estabilidade do regime democrático (INGLEHART, 1990 e 1997; OSTROM, 1990; ROSE, 1994; MISHLER e ROSE, 1997; NEWTON, 1997; ROSE, MISHLER e HAERPFER, 1998; DALTON, 1999).

O modelo supõe a existência de padrões culturais duradouros que permitiriam explicar diferenças de longo prazo entre nações, a exemplo de traços como deferência diante da autoridade, solidariedade, capacidade de cooperar com metas coletivas ou apoio político baseado no sentimento de identidade nacional. Inglehart (1999), em particular, reporta-se à evidência encontrada de que a associação de certos padrões culturais, como orientações religiosas, prevalece para explicar cadeias causais de orientações intersubjetivas quanto ao regime político. É discutível, contudo, se a ênfase analítica posta no processo de socialização e, em conseqüência, na interveniência de longa duração no tempo de valores sociais introjetados pelos indivíduos é suficiente para explicar mudanças repentinas de atitudes do público a respeito do funcionamento de parlamentos, partidos políticos ou do judiciário, como muitas vezes ocorreu em anos recentes. Sem descartar completamente o efeito desses fatores, eles precisam ser tratados em associação com outras dimensões capazes de explicar os nexos causais da confiança. Por outro lado, nem sempre a pesquisa associada a essa abordagem teve êxito para fazer a necessária conexão entre a dimensão micro da política, expressa pela opinião dos indivíduos, e a macro, representada pelas estruturas institucionais (BRINT, 1991).

Teorias de desempenho econômico - Uma alternativa importante aos modelos anteriores, inspirada em teorias econômicas clássicas e neoclássicas, associa o fenômeno da confiança política ao desempenho econômico de governos e de lideranças políticas. A suposição é que o fenômeno não é estável e que suas flutuações refletiriam basicamente a avaliação cambiante dos cidadãos a respeito da performance de governos e de políticos e, em especial, de sua capacidade para administrar a economia de modo a atender as demandas dos eleitores. A premissa é que quando se verifica a capacidade de governos e autoridades para agirem continuadamente de acordo com a expectativa dos cidadãos - algo que se forma a partir dos ciclos eleitorais -, produz-se apoio generalizado ao regime político. Dessa forma, boa parte dos estudos baseados nessa concepção concentraram-se nos efeitos de níveis agregados de fatores econômicos - como inflação, desemprego ou crescimento econômico - sobre os índices de apoio público a governos e 
instituições políticas e, ainda que diferente em cada caso, concluíram que a confiança é uma função do desempenho governamental (WEIL, 1989; KORNBERG e CLARKE, 1992; WEATHERFORD, 1991 e 1992; ANDERSON, 1995).

Certamente atrativa por propor uma perspectiva racionalista da confiança política, oposta às considerações sócio-psicológicas ou socioculturais, a abordagem do desempenho econômico tem, no entanto, seus limites. Desempenho governamental positivo traduz-se, entre outras coisas, em crescimento econômico, o que significa que países que conheceram taxas significativas de crescimento, ao longo do tempo, deveriam exibir índices elevados de confiança política; os resultados positivos embasariam a opinião dos cidadãos e influenciariam a sua avaliação de governos e instituições. No entanto, várias experiências recentes desconfirmaram isso: em alguns casos, índices consistentes e continuados de cinismo em países como Itália e Japão conviveram, a partir do segundo pós-guerra, com crescimento econômico rápido, continuado e significativo (MORLINO e TARCHI, 1996; PHARR, 1997). No caso mais discrepante, o dos Estados Unidos, a confiança política declinou drasticamente desde os anos 1960, caindo de 2/3 de apoio para menos de 1/3, apesar da prosperidade econômica do período (LAWRENCE, 1997). Isso levou alguns autores a sugerir que a noção de desempenho deveria incluir fatores extra-econômicos, a exemplo de variáveis políticas e simbólicas (MCALLISTER, 1992). No caso da situação norte-americana, algumas análises incluíam nos modelos explicativos os efeitos de acontecimentos como a guerra do Vietnã e o caso Watergate, sugerindo que era necessário levar em conta as percepções quanto ao sentido de probidade e justiça das ações de autoridades públicas para avaliar o apoio político, mas isso viola os pressupostos originais da teoria. Além disso, pesquisas recentes mostraram que o fenômeno da confiança política associa-se preferencialmente a fatores políticos ao invés de variáveis de natureza instrumental, como as relativas ao desempenho econômico (DALTON, 1999).

Teorias institucionais - A abordagem alternativa mais importante parte da noção segundo a qual as instituições, como regras normativas de comportamento um fenômeno estável nas democracias, caracterizado por padrão incrementalista de desenvolvimento - exercem uma influência decisiva para a geração da confiança política. A justificação e os padrões de funcionamento das instituições encerrariam a chave para explicar as causas da confiança: contrastando com as outras perspectivas, essa abordagem sustenta que a confiança política distribui-se aleatoriamente entre diferentes tipos de personalidade individual, contextos socioculturais ou padrões de desempenho econômico de governos (NORRIS, 1999). Instituições cujo funcionamento é compatível com a expectativa suscitada por sua justificação normativa, associada às suas funções permanentes, tenderiam a gerar a 
confiança dos cidadãos, enquanto aquelas cujo desempenho contraria ou frustra essa expectativa provocariam suspeição, sentimentos de distanciamento e rejeição, gerando baixos níveis de confiança política ou simplesmente desconfiança. A suposição é que as instituições funcionam bem se, coerentes com seus fundamentos legais e sua legitimidade, sinalizam imparcialidade, universalismo, probidade e justeza na relação com os cidadãos, ganhando a sua confiança e, assim, constituindo-se em referencial de seu comportamento político (GIDDENS, 1989; OFFE, 1999; NORRIS, 1999; LEVI, 1999; DURAND PONTE, 2004).

A abordagem retoma uma idéia original de David Easton com relação ao apoio político específico e ao apoio político difuso ao sistema político como dimensões diferentes: enquanto o primeiro se refere à satisfação dos cidadãos com o desempenho de governos e das elites governativas, o apoio difuso diz respeito à atitude dos cidadãos em relação ao sistema político em seu conjunto, independentemente do desempenho de seus responsáveis (1965, caps. 11-13 e 17 . 21 ; 1975). A distinção também foi utilizada por Lipset com os conceitos de efetividade e de legitimidade (LIPSET, 1981) e tem implicações para a motivação dos cidadãos de participar de processos de tomada de decisões que afetam a comunidade a que pertencem, permitindo que ajam com vistas à realização de suas aspirações e interesses, e formando a base da orientação avaliativa que assumirão sobre como e quanto governos e instituições são capazes de responder às expectativas normativas geradas pela ordem institucional (STOKES, 1962; MILLER, 1974).

O compromisso dos cidadãos com os fundamentos que incluem direitos e deveres de cidadania, traduzido pela mediação de instituições desenhadas para regular a esfera pública, conformaria o que alguns autores chamaram de cultura a partir da qual se pode falar em confiança política. Essa cultura expressar-se-ia em termos de um conjunto de regras, normas e valores cujo complexo regula a oferta, a procura e a reciprocidade da confiança (SZTOMPKA, 1999; WARREN, 1999). A desconfiança política corresponderia ao oposto disso, ou seja, à situação em que os cidadãos sentem-se desrespeitados por procedimentos institucionais ilícitos ou não autorizados, a exemplo de eleições irregulares ou fraudulentas, corrupção e comportamento anti-republicano de governos e políticos; ou, ainda, quando os cidadãos não encontram motivos para acreditar que instituições como as agências de serviços públicos funcionam de acordo com o fim para o qual existem ou com a eficiência necessária ao cumprimento de sua missão; e, finalmente, quando estão convencidos de que alguns entre eles têm mais acesso a direitos civis, políticos e sociais do que outros - ao contrário do que preconizam a constituição e as leis do país (NORRIS, 1999; NYE et al., 1997; LEVI, 1999). 


\section{Confiança e experiência}

A sugestão de Easton segundo a qual o fenômeno da confiança política se relaciona com a experiência das pessoas foi retomada por essa abordagem das instituições. Nesse caso, os membros da comunidade política são vistos como se identificando com as instituições porque aprenderam a fazê-lo através de processos sucessivos de transmissão de seu significado de geração a geração mas, principalmente, porque suas experiências concretas, ao longo de sua vida adulta, qualifica-os para avaliar racionalmente o seu desempenho. Essa avaliação incluiria a percepção de resultados decorrentes do desempenho das instituições, a exemplo de avanços sociais ou econômicos, mas, uma vez que essa avaliação passasse a fazer parte da rotina das pessoas, levaria à percepção da diferença entre desempenho específico e funções permanentes das instituições. O público reconheceria e avaliaria criticamente as instituições a partir do que aprendeu que é a sua missão fundamental, reagindo a elas de acordo com essa percepção (EASTON, 1975). Offe argumentou em sentido semelhante ao defender, recentemente, que a confiança nas instituições depende do quanto seus gestores conseguem traduzir para os cidadãos, através de seu funcionamento prático, a idéia básica ou o valor - "o repertório de significações e de justificações" - que funda e articula cada instituição específica; a complacência ou a concordância dos cidadãos em face de regras de comportamento emanadas da ação dos gestores das instituições dependeria dessa capacidade discursiva das instituições (OFFE, 1999).

Experiências significativas para informar a avaliação dos cidadãos a respeito das instituições referem-se, ao mesmo tempo, a procedimentos definidos pelos arranjos constitucionais, escritos ou não, baseados em padrões ético-políticos decorrentes do princípio de igualdade de todos perante a lei e às avaliações práticas mencionadas antes. Uma vez que sejam capazes de sinalizar, de modo claro, o universalismo, a imparcialidade, a justeza e a probidade de seus procedimentos - Offe fala da capacidade das instituições de ater-se à "verdade" dos fatos e de cumprir as promessas implicadas por sua missão -, as instituições assegurariam que os diferentes interesses em jogo fossem levados em conta pelo sistema político. Por isso, políticas públicas resultantes desse complexo de procedimentos, cujo acesso se supõe estar assegurado ao conjunto dos membros da comunidade política, permitiriam aos cidadãos informar-se e acompanhar os processos de tomada de decisões coletivas que os afetam, em cuja situação as instituições seriam tomadas como referência de suas disputas democráticas, assegurando que perdedores do presente pudessem tornar-se vencedores no futuro. A regra é universal e diz respeito a direitos de cidadania assegurados pelos 
sistemas eleitorais e de partidos, a parlamentos, tribunais de justiça e a normas relativas à probidade da administração pública (WARREN, 1999).

As instituições operam, portanto, como marcos de previsibilidade da ação de governos e de seus responsáveis a partir de regras que organizam o seu desempenho e permitem que sua ação seja controlada socialmente através de normas de imparcialidade e de correção de desvios. Se a experiência prática confirma isso, ao longo do tempo, a submissão e a adesão dos cidadãos às instituições é correspondida pelo funcionamento eficiente e adequado de governos, quaisquer que sejam suas orientações. Mas o contrário acontece se governos, autoridades e instituições tratam a confiança depositada neles pelos cidadãos através de sua participação em eleições e da aceitação de decisões que os afetam sem a devida reciprocidade (LEVI, 1998; NORRIS, 1999).

Por outro lado, a diversidade das experiências dos cidadãos com as instituições origina a multidimensionalidade da confiança política. Por essa razão, abordagens recentes do fenômeno identificaram cinco níveis de apoio político a serem considerados pela pesquisa do tema: (1) à comunidade política per se, (2) aos princípios do regime democrático, (3) ao desempenho específico do regime, (4) às instituições democráticas e (5) aos atores políticos. O primeiro nível refere-se ao modo pelo qual os cidadãos se vinculam ao Estado-nação, isto é, às fronteiras territoriais e políticas que definem a sua identidade coletiva (LINZ e STEPAN, 1996). Orgulho, lealdade e expectativas relativas às suas aspirações sociais, étnicas ou religiosas são alguns dos sentimentos correspondentes; a ligação dos cidadãos com sua comunidade política seria parte de um quadro específico que favorece a confiança social e o engajamento cívico (NEWTON, 1999). O segundo nível alude à adesão dos cidadãos ao regime democrático como um ideal, isto é, aos valores que, mesmo sem se constituir em um consenso absoluto, distinguem esse regime dos demais; ou seja, admitindo que a democracia tem significados diferentes para pessoas diferentes de sociedades diferentes (THOMASSEN, 1995; SIMON, 1996; MILLER, HESLI e REISINGER, 1997), alguns valores a definem em oposição a outros regimes: as noções de liberdade, império da lei, eqüidade, participação, tolerância em face da diferença e respeito por direitos e deveres estabelecidos constitucionalmente (BEETHAM, 1994; SIMON, 1996). O terceiro nível permite verificar o funcionamento prático da democracia, isto é, o desempenho concreto do regime no dia a dia em contraste com o seu significado ideal. Para isso, importam menos as percepções dos cidadãos sobre os princípios do regime democrático e mais sobre a sua capacidade de solucionar problemas socialmente percebidos como prioritários (MCDONOUGH et al., 1999; MOISÉS, 1995; FUCHS, 1995). Essa distinção permite captar, de modo mais adequado, as avaliações individuais sobre o desempenho específico do sistema democrático, em dado momento e lugar, em contraste com a percepção de suas vantagens em relação a outros regimes 
(KLINGEMANN, 1999). O quarto nível refere-se às instituições democráticas e abrange o universo de atitudes e percepções dos cidadãos a respeito de parlamentos, partidos políticos, executivo, judiciário, sistema legal, serviços públicos como educação, saúde e segurança pública, burocracia estatal e as forças armadas, em contraposição ao desempenho de seus ocupantes ou líderes ocasionais (LIPSET e SCHNEIDER, 1983; LISTHAUG e WIBERG, 1995); a ênfase é posta nos objetivos finalísticos das instituições e na expectativa que geram, menos do que em resultados práticos (HIBBING e THEISS-MORSE, 1995). O último nível analítico refere-se ao apoio dos cidadãos aos atores políticos, isto é, aos líderes e membros do segmento que se convencionou chamar de "classe política": o objetivo é examinar a avaliação pública que emerge de seu desempenho específico e, desta forma, manter a distinção entre essa dimensão e a que se refere à confiança ou desconfiança em governos e instituições políticas (ROSE, 1995).

Em resumo, a especificidade da concepção defendida neste artigo está em que a explicação do fenômeno de confiança em instituições radica nas próprias instituições e não na confiança interpessoal. Isso se refere ao sentido ético e normativo da mediação que elas implicam, para o que contam seus fins, sua justificação e seus meios de funcionamento. Essa significação ético-política das instituições tem raiz no contexto social que lhes dá origem - do qual fazem parte as orientações intersubjetivas dos cidadãos -, mas isso não exclui que a permanente atualização dessa significação envolva, ao mesmo tempo, o aprendizado que decorre da avaliação que os cidadãos fazem do desempenho concreto das instituições a partir de sua experiência. Por isso, não há motivo para contrapor a motivação normativa à racionalidade decorrente dessa avaliação e do julgamento que ela suscita.

\section{Referências Bibliográficas}

ALLPORT, G. W. Pattern and growth in personality. New York: Holt, Rinehart and Winston, 1961.

ALMOND, G.; VERBA, S. The civic culture: political attitudes and democracy in five nations. Princeton: Princeton University Press, 1963.

ANDERSON, C. Blaming the government: citizens and the economy in five european countries. Armonk, NY: M. E. Sharpe Press, 1995. 
BEETHAM, D. (Ed.). Defining and measuring democracy. London: Thousand Oaks, CA: Sage, 1994.

BELLAH, R. N. et al. Habits of the heart: individualism and commitment in american life. Berkeley: University of California Press, 1985.

BOBBIO, N. O futuro da democracia: uma defesa das regras do jogo. Rio de Janeiro: Paz e Terra, 1984.

BRAITHWAITE, V. Communal and exchange trust norms: their value base and relevance to institutional trust. In: BRAITHWAITE, V.; LEVI, M. (Eds.). Trust and governance. New York: Russell Sage Foundation, 1998.

BRINT, M. A genealogy of political culture. Boulder, Colorado: Westview, 1991.

CATTELL, R. B. The scientific analysis of personality. Harmondsworth: Penguin Books, 1965.

CHAGAS, H. Relações executivo-legislativo. In: LAMOUNIER, B.; FIGUEIREDO, R. A era FHC: um balanço. São Paulo: Cultura Editores Associados, 2002.

CITRIN, J. Comment: the political relevance of trust in government. American Political Science Review, v. 68, n. 3, p. 973-88, 1974.

COHEN, J. Trust, voluntary association and workable democracy: the contemporary American discourse of civil society. In: Warren, M. (Ed.). Democracy and Trust . Cambridge: Cambridge University Press, 1999.

COLEMAN, J. S. Foundations of social theory. Cambridge: Belknap Press, 1990.

DAHL, R. A. A preface to democractic theory. Chicago: The University of Chicago Press, 1956. . Democracy and its critics. New Haven, Connecticut: Yale University Press, 1989.

DALTON, R. Political support in advanced industrial countries. In: NORRIS, P. (Ed.). Critical citizens: global support for democratic government. Oxford: Oxford University Press, 1999.

D'ARAUJO, M. C. et al. Visões do Golpe: a memória militar sobre 1964. Rio de Janeiro: Relume Dumará, 1994.

DURAND PONTE, V. M. Ciudadania y cultura política. México 1993-2001. [S.L.] México: Siglo XXI Editores, 2004. 
EASTON, D. A systems analysis of political life. New York: Wiley, 1965.

. A re-assessment of the concept of political support. British Journal of Political Science, v. 5, n. 4; p. 435-57, 1975.

FUCHS, D. Support for democratic system. In: KLINGEMANN, H.-D.; FUCHS, D. (Eds.). Citizens and the state. Oxford: Oxford University Press, 1995.

FUKUYAMA, F. Trust: the social virtues and the creation of prosperity. New York: Free Press, 1995.

GABRIEL, O. Political efficacy and trust. In: VAN DETH, J. W.; SCARBROUGH, E. The impact of values. Oxford: Oxford University Press, 1995.

GIDDENS, A. A constituição da sociedade. São Paulo: Martins Fontes, 1989.

. The consequences of modernity. Cambridge: Polity, 1990.

GRAEFF, E. O vôo do besouro: política partidária e processo decisório no governo Cardoso.

Comunicação apresentada ao V Congresso da Brazilian Studies Association, 2000.

HADENIUS, A. Institutions and democratic citizenship. Oxford: Oxford University Press, 2001.

HARDIN, R. Do we want trust in government?. In: WARREN, M. E. (Ed.). Democracy and trust. [Cambridge]: Cambridge University Press, 1999.

HARRE, R. Trust and its surrogates: psychological foundations of political process.

In: WARREN, M. E. (Ed.). Democracy and Trust. Cambridge: Cambridge University Press, 1999.

HETHERINGTON, M. J. The political relevance of political trust. American Political Science Review, v. 92 , n. 4 , p. $791-808,1998$.

HIBBING, J. R.; THEISS-MORSE, E. Congress as public enemy. Cambridge: Cambridge University Press, 1995.

HUNTINGTON, S. The third wave: democratization in the late twentieth century. Norman: University of Oklahoma Press, 1991. 
INGLEHART, R. Culture shift in advanced industrial society. Princeton: Princeton University Press, 1990.

Modernization and postmodernization: cultural, economic and political change in 43 societies. Princeton: Princeton University Press, 1997.

. Trust, well-being and democracy. In: WARREN, M. E. (Ed.). Democracy and Trust. Cambridge: Cambridge University Press, 1999.

INGLEHART, R.; ABRAMSON, P. Economic security and value change. American Political Science Review, v. 88, n. 2, p. 336-54, 1994.

KLINGEMANN, H.-D. Mapping political support in the 1990s. In: NORRIS, P. (Ed.). Critical Citizens. Oxford: Oxford University Press, 1999.

KLINGEMANN, H.-D.; FUCHS, D. (Eds.). Citizens and the state. Oxford: Oxford University Press, 1995.

KLINGEMANN, H.; HOFFEBERT, R. I. Germany: a new 'wall in the mind'?. Journal of Democracy, v. 5, n. 1, p. 30-44, 1994.

KORNBERG, A.; CLARKE, H. D. Citizens and community: political support in a representative democracy. Cambridge; New York: Cambridge University Press, 1992.

KRAMER, R. M. Trust and distrust in organizations: emerging perspectives, enduring questions. Annual Review of Psychology, v. 50, p. 569-598, 1999.

LAGOS, M. Latin America's smiling mask. Journal of Democracy, v. 8, n. 3, p. 125-138, 1997. 2001. Between stability and crisis in Latin America. Journal of Democracy, v. 12, n. 1, p. 137-145,

LAWRENCE, R. Z. Is it really the economy, stupid?. In: NYE, J. S.; ZELIKOW, P. D.; KING, D. C. (Eds.). Why people don't trust government. Cambridge: Harvard University Press. 1997.

LEVI, M. A state of trust. In: BRAITHWAITE, V.; LEVI, M. (Eds.). Trust and governance. New York: Russell Sage Foundation. 1998.

When good defenses make good neighbors: a transaction cost approach to trust and distrust. New York: Russell Sage Foundation, Working Paper, n. 140, 1999. 
LINZ, J. J.; STEPAN, A. Problems of democratic transition and consolidation. Baltimore; London: The Johns Hopkins University Press. 1996.

LIPSET, S. M. Political Man: the social bases of politics. Baltimore: The Johns Hopkins University Press. 1981.

LIPSET, S. M.; SCHNEIDER, W. The confidence gap: business, labor, and government in the public mind. ed. rev. Baltimore: The Johns Hopkins University Press, 1983.

LISTHAUG, O.; WIBERG, M. Confidence in political and private institutions. In: KLINGEMANN, H.D.; FUCHS, D. (Eds.). Citizens and the state. Oxford: Oxford University Press. 1995.

LUHMANN, N. Trust: A mechanism for the reduction of social complexity. In: LUHMANN, N. (Ed.). Trust and Power. New York: John Wiley and Sons, 1979.

LUNDASEN, S. Podemos confiar nas medidas de confiança?. Opinião Pública, v. 8, n. 2, p. 304327, 2002.

MAINWARING, S. Rethinking party systems in the third wave of democratization: the case of Brazil. Stanford: Stanford University Press. 1999.

MARSHALL, T. H. Cidadania, classe social e status. Rio de Janeiro: Zahar. 1967.

MCALLISTER, I. Political Behavior. Melbourne: Longman Cheshire Press. 1992.

MCDONOUGH, P.; SHIN, D. C. ; MOISES, J. A. Democratization and participation: comparing Spain, Brazil, and Korea. Journal of Politics, v. 60, p. 919-921, 1988.

. The economic performance of governments. In: NORRIS, P. (ed.) Critical citizens: global support for democratic governance. New York: Oxford University Press, 1999. p. 188-203.

MILLER, A. H. Political issues and trust in government, 1964-70. American Political Science Review, v. 68 , n. 3 , p. $951-72,1974$ a.

. Rejoinder to 'Comment' by Jack Citrin: political discontent or ritualism?. American Political Science Review, v. 68, n. 3, p. 989-1001, 1974b.

MILLER, A. H.; HESLI, V.; REISINGER, W. M. Conceptions of democracy among mass and elite in post-soviet societies. British Journal of Political Science, v. 27, n. 2, p. 157-90, 1997. 
MILLER, A. H.; LISTHAUG, O. Political performance and institutional trust. In: NORRIS, P. (Ed.). Critical citizens: global support for democratic governance. New York: Oxford University Press, 1999.

MISHLER, W.; ROSE, R. Support for parliaments and regimes in the transition toward democracy. Legislative Studies Quarterly, v. 19, n. 1, p. 5-32, 1994.

. Trust, distrust and skepticism: popular evaluations of civil and political institutions in postcommunist societies. Journal of Politics, v. 59, n. 2, p. 418-51, 1997.

. Learning democracy: the dynamics of popular support for post-communist regimes. Reunião da American Political Science Association, Atlanta, setembro 1999.

MOISÉS, J. A. Sociedade civil, cultura política e democracia: descaminhos da transição política. In: COVRE, M. L. et al. A cidadania que não temos. São Paulo: Brasiliense, 1986.

. Dilemas da consolidação democrática no Brasil. In: MOISÉS, J. A.; ALBUQUERQUE, J. A. G. Dilemas da consolidação da democracia. Rio de Janeiro: Paz e Terra, 1989.

. Elecciones, participación y cultura política en Brasil: cambio y continuidad. Revista Española de Investigaciones Sociales, n. 50, p. 61-109, 1990.

. Democratização e cultura política de massas no Brasil. Lua Nova, n. 26, p. 5-51, 1992.

. Impasses para a consolidação da democracia no Cone Sul: a tradição presidencialista. Debates, Fundação Konrad-Adenauer, v. 1, 1993a.

Perspectivas de consolidação da democracia na América Latina. In: MOISÉS, J. A. et al. Perspectivas da América Latina nos anos 90. Fundação Alexandre Gusmão; Núcleo de Pesquisa em Relações Internacionais e Política Comparada da USP, 1993b.

Partidos y gobernabilidad en Brasil: obstáculos institucionales. Nueva Sociedad, n. 134, p. $\overline{158-71}, 1994$

Os brasileiros e a democracia. São Paulo: Ática. 1995.

et al. Democratization and participation: comparing Spain, Brazil and Korea. The Journal of Politics, v. 60, n. 4, p. 919-53, 1998.

et al. The churches and political mobilization in Brazil, Korea and Spain. In: YESILADA, B.

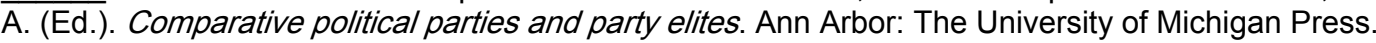
1999. 
MORLINO, L.; TARCHI, M. The dissatisfied society: roots of political change in Italy. European Journal of Political Research, v. 30, n. 1, p. 41-63, 1996.

MOUFFE, C. Democratic Citizenship and the Political Community. In: MOUFFE, C. (ed.). Dimensions of radical democracy: pluralism, citizenship, community. London: Verso, 1992. p. 225239.

NEWTON, K. Social capital and democracy. American Behavioral Scientist, v. 40, n. 5, p. 575-86, 1997.

Social and political trust in established democracies. In: NORRIS, P. (Ed.). Critical citizens:

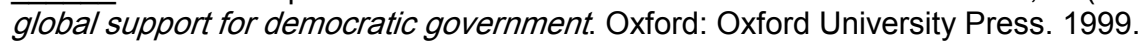

NEWTON, K.; NORRIS, P. Confidence in public institutions: faith, culture or performance?. In: PHARR, S. J.; PUTNAM, R. D. Disaffected democracies: what's troubling the trilateral countries?. Princeton: Princeton University Press, 2000.

NORRIS, P. The growth of critical citizens?. In: NORRIS, P. (Ed.). Critical citizens: global support for democratic government. Oxford: Oxford University Press. 1999.

NYE, J. S. et al. Why people don't trust government. Cambridge: Harvard University Press, 1997.

OFFE, C. How can we trust our fellow citizens?. In: WARREN, M. E. (Ed.). Democracy and trust. Cambridge: Cambridge University Press, 1999.

OSTROM, E. Governing the commons: the evolution of institutions for collective action. Cambridge; New York: Cambridge University Press, 1990.

PETTIT, P. Republican theory and political trust. In: BRAITHWAITE, V.; LEVI, M. (Eds.). Trust and governance. New York: Russell Sage Foundation, 1998.

PHARR, S. Political trust and democracy in Japan. In: NYE, J. S.; ZELIKOW, P. D.; KING, D. C. (Eds.). Why people don't trust government. Cambridge: Harvard University Press, 1997.

PHARR, S. J.; PUTNAM, R. D. Disaffected democracies: what's troubling the trilateral countries?. Princeton: Princeton University Press, 2000.

PUTNAM, R. D. The prosperous community: social capital. The American Prospect, v. 4, n. 13, p. 35-42, 1993. 
Schuster, 2000.

Bowling Alone: collapse and revival of american community. New York: Simon and

ROSE, R. Post-communism and the problem of trust, Journal of Democracy, v. 5, n. 3, p. 8-30, 1994. $\overline{71,1995}$

Freedom as a fundamental value. International Social Science Journal, v. 47, n. 145, p. 457-

ROSE, R.; MISHLER, W.; HAERPFER, C. Social capital in civic and stressful societies. Studies in International Comparative Development, v. 32, n. 3, p. 85-111, 1997.

ROSENBERG, M. Misanthropy and Political Ideology. American Sociological Review, v. 21, p. 690695, 1956.

Misanthropy and attitudes toward international affairs. Journal of Conflict Resolution, v. 1, n. 4, p. 340-45, 1957.

SANTOS, W. G. Sessenta e quatro: anatomia da crise. São Paulo: Vértice, 1986.

SARTORI, G. Teoria Democrática. Rio de Janeiro: Fundo de Cultura, 1965.

SELIGMAN, A. B. The Problem of Trust. Princeton: Princeton University Press, 1997.

SILVA, G. do C. e. Conjuntura política nacional: o poder executivo e geopolítica do Brasil. Rio de Janeiro: José Olympio, 1981.

SIMON, J. Popular ideas of democracy in post-communist Europe. Studies in Public Policy, University of Strathclyde, n. 273, 1996.

SKIDMORE, T. Brasil: de Getúlio Vargas a Castelo Branco. Rio de Janeiro: Editora Saga, 1969.

STOKES, D. E. Popular evaluations of government: an empirical assessment. In: CLEVELAND, H.; LASSWELL, H. D. Ethics and bigness: scientific, academic, religious, political and military. Harper and Brothers, 1962.

STOKES, S. Mandates and democracy. Studies in comparative international development, v. 37, n. 3, fall 2002.

SZTOMPKA, P. Trust and emerging democracy. International Sociology, v. 11, n. 1, p. 37-62, 1996. 
Trust: a sociological theory. Cambridge: Cambridge University Press, 1999.

THOMASSEN, J. Support for democratic values. In: KLINGEMANN, H.-D.; FUCHS, D. (Eds.). Citizens and the state. Oxford: Oxford University Press, 1995.

TYLER, T. R. Trust and democratic governance. In: BRAITHWAITE, V.; LEVI, M. (Eds.). Trust and governance. New York: Russell Sage Foundation, 1998.

USLANER, E. M. Volunteering and Social Capital: How Trust and Religion Shape Civic Participation in the United States. In: DEKKER, P.; USLANER, E. M. (eds.). Social Capital and Participation in Everyday Life. London and New York: Routledge, 2001.

. The Moral Foundations of Trust. New York: Cambridge University Press, 2002.

WARREN, M. E. Democratic theory and trust. In: WARREN, M. E. (Ed.). Democracy and trust. Cambridge: Cambridge University Press, 1999.

. Democracy and association. Princeton: Princeton University Press, 2001.

WEATHERFORD, S. M. Mapping the ties that bind: legitimacy, representation, and alienation. Western Political Quarterly, v. 44, n. 2, p. 251-76, 1991.

1992.

Measuring political legitimacy. American Political Science Review, v. 86, n. 1, p. 149-66,

WEIL, F. D. The sources and structure of legitimation in western democracies. American Sociological Review, v. 54, n. 5, p. 682-706, 1989.

WILLIAMS, J. T. Systemic influences on political trust: the importance of perceived institutional performance. Political Methodology, v. 11, n. 1-2, p. 125-42, 1985. 